\title{
Interpreter's Position in the Process of Interpretation
}

\author{
Jia Yao \\ College of Foreign Languages, CTGU, Yichang, China \\ Email:254059124@qq.com
}

How to cite this paper: Yao, J. (2021) Interpreter's Position in the Process of Interpretation. Open Journal of Applied Sciences, 11, 422-439.

https://doi.org/10.4236/ojapps.2021.114031

Received: February 25, 2021

Accepted: April 18, 2021

Published: April 21, 2021

Copyright $\odot 2021$ by author(s) and Scientific Research Publishing Inc. This work is licensed under the Creative Commons Attribution-NonCommercial International License (CC BY-NC 4.0). http://creativecommons.org/licenses/by-nc/4.0/ (c) (i) (8) Open Access

\begin{abstract}
With the rapid development of globalization, the whole world interweaves unprecedentedly. The frequent global communication is in desperate need of qualified translators and interpreters which draws great attention and invokes discussion about the standard of translation. Is the widely acknowledged criterion-neutral position a possible and necessary regulation to justify professional translators? This essay will illustrate that the interpreters influenced by environment, culture and other factors can't perform with an absolute neutral position. Furthermore, the creativity of interpreters, who conduct heuristic work instead of algorithmic and reduplicated work, play a pivotal role in qualified work and their long-term development on the basis of Skopos Theory and classical examples, which testifies that it is improper to regard neutral position as a significant standard to evaluate the quality of interpreters.
\end{abstract}

\section{Keywords}

Interpreters' Position, Skopos Theory, Interpretation Standard, Driving Force Theory

\section{Introduction}

There has been more than two thousand years of translation, the study of translation theory, however, didn't start until recent hundreds of years. The majority of the well-known theories give priority to faithfulness both in the Orient and the Occident. The distinguished Chinese scholar Yan Fu put forward a threecharacter standard in translation-faithfulness, expressiveness and elegance. Lu Xun, a great writer, thinker, proposed-faithfulness and smoothness. He has fought against the tendencies of irresponsible translation in the first decade of the century and given particular importance to faithfulness-The value of a translation lies in its faithfulness to the original text. Nida's Dynamic Equivalence 
Theory also attaches much importance to faithfulness. At the same time, no wander that the translators' effects are highly undermined and requested to be neutral and invisible in the process of translation.

However, as the study into human and translation going forward, the subjectivity of translators become more and more prominent. The focus of translation didn't only fix on the equivalence between the original language and target language, but instead, try to observe more the effect of translators themselves. Under such trend, the feasibility of the customary standard of translation plunge into doubt, the core problem is whether a person can perform with absolutely neutral attitudes apart from the influence of personal judgments and emotions, especially in trans-cultural activities, not mention there is no explicit explanation of neutral position.

This essay will demonstrate, based on Skopos Theory, driving forces theory and authentic examples, the theoretical complete neutrality is impossible to carry out in practice. Besides, translators' creativity and subjectivity are not only indispensable but also helpful in completing excellent translation works according to driving force theory. The research purpose is to justify the possibility of interpreting performance with an absolute neutral position.

\section{Theoretical Background}

\section{Translation}

Generally speaking, translation is a transformation process, turning original text into target text, which includes two steps: decoding and re-coding. The third party-translators should, firstly understand the intonation and purpose of the original text and then try to explain in target language. However, since the emergence of translation, the discussions about its definition and nature have never suspended. There are three widely acknowledged theories about the definition of translation: a science, a skill and an art.

Wolf Wilss thinks that translation is cognitive, hermeneutic and associative science. According to Carlos Hernandez-Sacristan, translation as a natural skill is developed by means of performance of translating in sociosemiotic content and not as a function of cognitive maturation of early bilinguals, nor something linked to biological age. And according to Fu Lei-Translation is an art of languages and artistic beauty that translation possesses is a product that the translator creatively shapes according to aesthetic laws. When he turns an original into a translation, what the translator experiences is a recreative process. Without the process of creation, the artistry of a translation would be out of the question.

From my perspective, translation, primarily, is a branch of science and should be studied by logical and systematical methods. Instead of one field only about language, a mixture of multi-fields is more appropriate to describe translation. When treating translation with scientific attitude, we can fully comprehensive the nature of translation. When talking about translation, we do not concern about 
the language itself, but also the culture factor embodied in language. As the study into translation going forward, we gradually discover the law and master it, and then, translation can be called a skill. In the end, it is not until the translation works turn from simple unit of research results into art masterpieces, they fulfilled the mission - that is to say, art is the final manifestation of translation. According to Malclom Cowley, a famous translation theorist-Translation is an art that involves the recreation of a work in another language for readers with a different background. Translation is only a job involved in the equivalence between original language and target language, but a recreation process with translators' understandings and creativity. Both parties-original writer and translation work together to create a masterpiece as much as possible.

\section{Skopos Theory}

\subsection{General Statement}

Katharina Reiss put forward the embryonic form of functional theory in translation in her Possibilities and Limitations in Translation Criticism published in 1971. She thought the ideal form of translation should be integral communicative performance-achieve equivalent with original text in terms of conceptual content, language form, communicative function [1]. Besides, she found that in reality, when there leaves few possibilities for absolute equivalence, translation work's purpose which may be different from the original one should be considered first instead of equivalence.

Based on the Katharina Reiss's study, a German scholar, her student-Vermeer, escaped from the restriction of both original text and target text and put the purpose of translation into priority, therefore put forward Skopos theory. Skopos, derived from Greek-skopos, now is used as a professional term to refer to the purpose or intention of translation. Skopos can be understood in three aspects: the translators' purposes (for money); translation works' communicative purposes (enlighten readers); purposes attained by some special methods (adopt literal translation method in order to explain the grammar structure in certain language).

Many Chinese writers and translators also have the similar thoughts. Lu Xun always insisted on being faithful to the literal translation of the original work. He once said before writing, we have to solve a problem: try to domesticate it or try to preserve it as much as possible. Lu Xun's answer to this question is very clear: translation should try to preserve the foreign atmosphere as much as possible. He believes that there are two purposes of Translation: one is to make the readers to feel the emotion of original work, the other is to enlighten. Similar to traveling abroad, there must be a foreign sentiment, that is, the so-called foreign atmosphere. Therefore, translation must keep the exotic flavour of the original text and do not advocate cutting the nose and gouging out the eyes of the original text. Second, in order to input new expression method, we should learn from the advantages of western languages to improve the expression of Chinese, so as to 
improve the grammar and syntax of Chinese. In order to achieve this goal, the translation method adopted is that in some places, it's even better for the translators to express awkwardly. If this translation method is only discussed from the technical level, it may lead to negative evaluation and even a complete denial. But if we combine Lu Xun's translation purpose to explore, I'm afraid we will get different evaluation. Lu Xun's translation method of direct translation or awkward translation is to achieve the translation purpose he advocated.

Within the framework of Skopos theory, translation means making a kind of text for the target readers in the target context. In contrast, the source text is subordinate. In other words, the source text is not in the centre position all the time, but an open entity with infinite possibilities, which is one of the various sources of information used by the translator. Therefore, the translator chooses certain information because he believes that the information can meet a certain purpose in the target culture. For example, the advertisement only has one purpose, which is to promote sales and increase the profit of customers. The most popular and satisfying advertisements translated are not works faithful to the original, such as Coca Cola. And there are specific, even immediate and utilitarian purposes, such as translating a press release for public relations, which must achieve the best effects; translating a section of passage for TV news program to host and read needs to attract more audience and increase audience rating; translating a book needs to sell well. To a great extent, the success or failure of translating such texts is measured by whether they can achieve these goals. Due to the special functions of-promotion and attraction and "exertion of influence" in advertising texts and the restriction of the language and structural form of the text type by the specific cultural characteristics, the translator should use the structural expression mode that conforms to the cultural concept of the target language according to the expected purpose or function of the target language, so that the target language can exert a good influence on the target language receiver. Therefore, in order to achieve the purpose of translation effectively, the translator should flexibly choose the corresponding translation strategies according to the expected functions of different texts, and decide which original text information can be retained in the specific context, which must be adjusted according to the context of the target language, and then according to the needs of the target readers, or literal translation, or free translation, or even deletion, adaptation, Otherwise, it may be detrimental to the realization of the intended purpose of the translation.

\subsection{Core Viewpoint}

Vermeer reckons all actions subject to purpose, including translation, that is to say, purpose of the translation determine the method of translation. Under this framework, the quality of translation works is determined by target readers with their own cultural and social background information instead of complete equivalence. Vermeer turned the focus form the meaningless discussion of original text-oriented or target text-oriented to the purpose of text, therefore, the choices 
are expanded for translators who can select more appropriate way rather than being stranded in the literal translation cycle.

Vermeer also come up with a theory called Translation Commission, which means translators are responsible for the whole translating task and have the rights to decide how to revise the text and adopt which translation method. If a translator accepts a translation task, the first thing he needs to do is to discuss the purpose with the original writer, rather than passively obeys the requirements of the clients. This theory free translators from the constraints of both source text and target text and have the ability to wield their creativity to make the translation works more like a beautiful masterpiece rather than a piece of formation of code. In addition, translators, who were once regard as callous machine doing the language transformation job, are taken from the behind into the stage where their talents can be better discovered and utilized.

Traditional translation theory always keep an eye on the original text, target text and their relationship, therefore, the evaluation standard sways from original text-oriented to target text-oriented and is hard to be fixed. Skopos theory expanded the translation methods and put forward new vision from different point of view. It liberalizes translators from the equivalence trap and formulates a series of related theories. Considering translation as a process with human purpose, thus it more focuses on the inner factors effecting translation and broaden the horizons of translation study.

\subsection{Driving Forces Theory}

\subsubsection{General Statement}

According to Daniel H. Pink's book Drive: The Surprising Truth about What Motivates Us, all the productive activities are divided into two parts: algorithmic work governed by left mind, including logic analysis ability and line-mode thinking ability mastered by accountants, lawyers and engineers; and heuristic work governed by the right mind, including artistic creative ability, compassionate ability, innovative ability and comprehensively thinking ability [2]. He reckons that on the basis of the former kind of work which has been focused and stressed since twentieth century, we should keep our eyes more on the second activity which may play a determining role in the unprecedentedly developing world.

Form $20^{\text {th }}$ century to nowadays, the motivation 2.0 system is still putting into effect, and its central idea is search for profits and avoid punishment. In the Industrial Revolution period, the invention of steam engine, the application of railway and universal use of electricity all significantly push forward the human society. At the same time, a new kind of management method was invented, which regarded all the workers as the materials of the complicated machines. If they do the right thing in the right time, the machine will operate well. In order to ensure above situation, the managers only need to encourage and award the right thing and punish you for your mistakes, so that after a while, workers can unconsciously follow the pattern input in your mind. This set of management method indeed increase the productivity quickly and permeate every corner of our 
lives thereof formulate our habits and way of thinking.

However, this kind of encouragement system kills people's initiative and creativity that gradually become the emotionless high-level machine and only obey the orders. In Alfie Kohn's book Punished by Rewards in 1993, he said though the motivation 2.0 system we used now can bring profit and benefits in a short time, the destructive influence exerted on human' hope and interests towards life and their future cannot be converted. Under this mode, people more likely to be disposable stuff, they chase the better material well-being life at expanse of the loss the original passion for self-satisfaction and self-improvement. Besides, the pessimistic impacts perform more obviously in heuristic work. If observing the outstanding and artists, we will find that their great work never born in certain regulated time or space and they just follow the flow of heart and let the inner desire of expression burst. Researchers said, the reasons why some artists devote themselves into the process of the creation of work are the happiness the creation itself owns rather than the external rewards, furthermore, they win the recognition of the society through their great works. The inner motivation-you want to do one thing because it is charming, fascinating, and challengeable, play a pivotal role in higher level creativity.

\subsubsection{Application in Interpretation}

The diving forces theory can be applied in every industry. The rewards are beneficial for the jobs that obey the existed rules and calculate reasonable results. Interpretation, in most part, relies on the immediate performance which substantially should be regarded as a heuristic job. Interpreters are required to respond as exactly and quickly as possible which can't turn to the duplication of the original speaker. They should carry on analysis of the content of original speech, and do some necessary adjustment in regard to the features of target language. As we all know, liberal translation only lead to misunderstandings. Different from the written translation, interpretation more dependents on the immediate response of interpreters who should not only concern for the transformation of language, but also the surroundings and their own posture and facial expression which can exert great influence on the whole process of interpretation. If we ask the interpreters to obey the obscure regulation of neutral position otherwise they may restricted by the rules and cannot act according to the change of situation which to the great extent, is good and indispensable for the interpretation.

\section{Interpretation}

\subsection{General Statement}

Interpretation, as a special part of translation, requires, besides the basic requirements of translators, interpreters to do language transformation in a very short time as exactly as possible, which sets a very high threshold for professional interpreters. Different from written translation, which leaves capacious room for both readers and translators to peruse the intonation and usage the words, 
interpretation more relies on the immediate response and extensive knowledge accumulation of interpreters to great extent. Interpretation process is more like a working treadmill, all the people present, including the original speakers, target speakers and interpreters should concentrate on development and respond continuously [3]. Interpreters, instead of communicating by written forms, usually closely face the clients, and therefore, the small habits of interpreters, such as eye contact, tone, standing posters can become the suspicious reasons of impartiality. That is to say, the performance of interpreters directly matters final results of the communication. Interpreters, as a significant part of interpretation process, are affected by both the inner factors including the emotion, experience and the outer factors such as cultural background, environment.

\subsection{Neutrality}

Of the translation standard, neutrality plays an important role, which requires translators to stay neutral and get rid of the effects of emotional, political, religious factors. Such regulation is to safeguard the legal rights of both target and original clients, and keep fair so that ensure the consequence is free from the interference of dispensable things. It is reasonable to set neutrality as one of the fundamental rule, but is it practical in reality?

As a matter of fact, the definition of neutrality itself is obscure, and may can be understood as same as the definition of fair, impartiality. Neutrality demands translators to clearly and fully express and explain the meaning of original speaker without any personal position and points. In the process of translation, translators, under most circumstances, are considered as bridges connecting source language and target language. The performance of translators directly relate with the consequence of communication results. The famous American translation theoretician Eugene A. Nida thinks that-translation consists in reproducing in the receptor language the closest natural equivalent of the source language, first in terms of meaning and secondly in terms of style. Above all, on the one hand, interpreters are requested to express exactly from the source language speakers to target language speakers without any personal emotion or inclination. On the other hand, interpreters should act formally as much as possible, any small gestures including smile, sitting posture, eye contact could be classified into unjustified behavior in interpretation.

Although, neutral position is a significant rule in translation associations and UN, they provide little practical guidance to clarify how to achieve neutral position in translation, which leaves room for the disputes. Besides, is the neutral position definitely beneficial for the intercultural communication? If the clients regard the translators have partial behavior, how to prove that their performance violate the neutrality regulation.

In the process of interpreting, the two parties come from different language and culture systems. In order to achieve their respective communicative purposes, they gather together, and such intercultural communication is not neutral. 
First of all, from the perspective of macro cultural and social context, culture has never been neutral. Every nation and culture has its own history, experience, structure and characteristics. Culture is never neutral, no matter it is regarded as a whole of a specific social life style in a broad sense or defined as a value form with national spirit and temperament as the core in a narrow sense. Ethnocentrism is an inherent characteristic of almost all cultural systems. Almost every cultural unit will have an innate identification, affirmation, worship and maintenance of its own customs, historical traditions, system beliefs, values and lifestyle. At the same time, as the carrier of culture, language itself is also a part of culture cannot be neutral. Language symbols are not impartial. They not only reflect the experience of an individual or a group, but also represent a unique communication system generated from different experiences and histories. It can be said that any language is attached with a set of values and meanings covering social, historical, political, economic, cultural, national, psychological and other aspects Language not only reflects cultural values, but also has a significant impact on users' ideas. When people with different cultural identities and different cultural positions come together, carrying their own cultural tendency of ethnocentrism, and carrying their own cultural values and ideal language symbols for communication, such communication and dialogue cannot be completely neutral.

Translation is an aesthetic psychological activity. The process of translation is not an activity without motive or emotion, but a complex aesthetic psychological activity full of perception, emotion, imagination and understanding [4]. This kind of aesthetic psychological activity is reflected in: translation is not only faithful to the original text, but also shows the translator's subjective world; it is not only satisfied with the copy of the original text, but also contains the translator's creativity and style. The psychological process of examination and beauty is the empathy or peripheral process of the aesthetic subject. When appreciating or appreciating, people transfer or reflect their subjective feelings on the aesthetic object, and then appreciate and experience it. As a kind of translation activity, interpretation is full of the interpreter's motivation, perception, imagination and a series of aesthetic psychological activities. Therefore, the interpreter's subjective feelings will inevitably affect his understanding, reconstruction and output of the discourse. Thus, in the process of interpreting, it is difficult for an interpreter to completely avoid personal subjective feelings.

\subsection{Influence Factors in the Interpretation Process}

\subsubsection{Cultural Background}

Interpretation, generally speaking, belongs to a special intercultural activity which involves the third party-interpreters. Due to the gap between different cultures, the intercultural communication shines brightly with its charming and challengeable features. The growth environment cultivate different modes of thinking and social regulations of various cultures, one thing may be cherished in one culture, but detested in another. How to find the balance and build a bridge be- 
tween cultures has been a question bothering scholars for a long time. Interpreters, as the particular traits, directly involve even determine the ends in the intercultural communication.

Interpreters tend to understand to original speakers in their own way and try to find the supplementary staff between cultures in a very short time. During the process of interpretation, there may be no direct counterpart of different cultures, interpreters tend to fathom the intention of speaker consciously or unconsciously to ensure exact translation results, which means they are inevitably disturbed by both parties. Therefore, undoubtedly, the information both original and target speakers receive features the interpreters' understanding. Some idioms or jokes only make some special effects in certain language such as laugh and irony, and neutral interpretation neither expresses the intonation of the original text, nor makes expected effects, but only to make environment awkward. Facing with such conditions, interpreters should no long obey the detachment rule but use their creativity to solve the problem, either get closer to the original text, or to the target text. Beautiful reply will add brilliance to their present splendour; however the awful treatment may even destroy the communication.

Instead of a mechanical activity, translation is more appropriate to be regarded as a complex aesthetic psychological activity involving thoughts, emotions, imaginations and understandings. Therefore, translation is bound to show the interpreters' subjectivity rather than simple language transformation from the original language to the target language; translation is in need of the creativity and style of interpreters not only satisfied with the reproduction of original text. Translation substantially is a kind of communication method between different cultures. Thus, interpreters will inevitably need to select the appropriate translation method so as to make the target readers understand as much as possible. In the process of cross-cultural dialogue-interpretation, it is indispensable for the third party-interpreters. Thus it can be seen that interpreters, as the intermediary of the two cultures, will inject their own cultural ideology into the process of understanding, rebuilding and reproducing the language.

\subsubsection{Interpreters' Knowledge Reservation}

As the difference of the language usage and way of thinking between Chinese and American, it is indispensable for interpreters to master the idioms and folk adage as much as possible. The lack of related knowledge might result in some pessimistic consequences. It is well acknowledged that the forms and meanings of the majority of idioms are changeable and various and always become the reason of misunderstandings. When confronting with unfamiliar expression, interpreters should brainstorm the equal or fungible words within in a short time, which requires quick response and to stay self-possessed, or else, their emotional ups and downs might be the uncertainty to the final results.

\section{Interpreters' Position in Different Situation}

Traditional translation theory reckons all the translation work should abide by 
the original text and try to be neutral as much as possible. But does this golden rule can be applied in any condition and definitely serve for better translation work? There will list some common situation in interpretation to discuss feasibility and necessity of neutral position.

\subsection{Chinese Central Literature}

Different from the common scientific and technological document, central document presents the spirit of China and our attitudes towards significant events both at home and abroad. That is to say, the interpreters of central document are the microphone of the Communist Party of China (CPC) and the Chinese government, instead of the third party, bystander, they are the ones who are responsible for the propaganda and presentation of China voices.

In the globalization world, China, as the biggest developing country, is trying to be an important part of the integrity and strives to get more discourse power, which partly relies on the translation to output China extraordinary traditional culture and the core spirit. China differs from other countries in several aspects: in history, ancient Chinese civilization is the only one that continues to this day; in culture, China cherishes collectivism while the westerners advocate individualism; in social system, China belongs to socialism camp while the western countries belong to capitalism camp; in international environment, developed western countries master the advanced technology and stand still in the central part of international stage, and China, as a promising youth do his endeavour to catch up. Under such circumstance, interpreters should no longer be the onlookers in the process of translation, instead, they should take the responsibility to gain more acknowledgement and minimize the misunderstanding so that to build a responsible great country image. Two thousand years ago, since the birth of Confucianism, Chinese nation has considered benevolence as the priority article of faith which is constantly abided by until nowadays. As long as we increase cultural export, the ridiculous parlance such as China threat theory will fall to the ground without being attacked.

Take the version of report delivered at the 19th National Congress of the Communist Party of China as an example:

站立在九百六十多万平方公里的广䘚土地上, 吸吮着五千多年中华民族漫 长奋斗积累的文化养分, 拥有十三亿多中国人民聚合的磅礴之力, 我们走中 国特色社会主义道路, 具有无比广阔的时代舞台, 具有无比深厚的历史底蕴, 具有无比强大的前进定力。

The English translation version:

Rooted in a land of more than 9.6 million square kilometers, nourished by a culture of more than 5000 years, and blessed with the strength of more than 1.3 billion people, we have an infinitely vast stage of our era, a heritage of unmatched depth, and incomparable resolve that enable us to forge ahead on the road of socialism with Chinese characteristics.

The Chinese version is imbued with rhetorical and descriptive expressions, 
which full presents the confidence for the bright future of Chinese nation. English translation version is more simple and clear and suitable for the English language usage. If, facing with such situation, interpreters attempt to do the translation exactly follow the steps of the original version, the text will be lengthy and jumble and decrease the momentum of securing a decisive victory in building a moderately prosperous society in all respects and strive for the great success of socialism with Chinese characteristics for a new era.

从现在到二 $\mathrm{O}$ 二 $\mathrm{O}$ 年, 是全面建成小康社会决胜期。要按照十六大、十七 大、十八大提出的全面建成小康社会各项要求, 紧扣我国社会主要矛盾变化, 统筹推进经济建设、政治建设、文化建设、社会建设、生态文明建设，坚定 实施科教兴国战略、人才强国战略、创新驱动发展战略、乡村振兴战略、区 域协调发展战略、可持续发展战略、军民融合发展战略，突出抓重点、补短 板、强弱项, 特别是要坚决打好防范化解重大风险、精准脱贫、污染防治的 攻坚战，使全面建成小康社会得到人民认可、经得起历史检验。

The English translation version:

The period between now and 2020 will be decisive in finishing the building of a moderately prosperous society in all respects. We must follow the requirements on building this society set out at our 16th, 17th, and 18th National Congresses, act in response to the evolution of the principal contradiction in Chinese society, and promote coordinated economic, political, cultural, social, and ecological advancement. We must show firm resolve in implementing the strategy for invigorating China through science and education, the strategy on developing a quality workforce, the innovation-driven development strategy, the rural vitalization strategy, the coordinated regional development strategy, the sustainable development strategy, and the military-civilian integration strategy. We must focus on priorities, address inadequacies, and shore up points of weakness. In this regard, I want to stress that we must take tough steps to forestall and defuse major risks, carry out targeted poverty alleviation, and prevent and control pollution, so that the moderately prosperous society we build earns the people's approval and stands the test of time.

Chinese language is prone to use four-character word to strength the express power, when translating into English, we should supply the necessary details to illustrate clearly the intonation of the words from the perspective of narrator. Translators should tell the Chinese story with understandable words in English to the whole world.

\subsection{Traditional Chinese Literature Translation}

In the Chinese traditional culture treasury, poem is absolutely a shining star explaining the splendid achievement. Chinese traditional poem, characterized by concise language, expressive and rhymed content, presents the charming of Chinese language and gradually become an important method of Chinese culture promotion. Due to the difference of history, environment, political system and other factors, China's behaviour is always misconceived by the international society especially the western countries, which therefore causes some unneces- 
sary conflicts and frictions. China, from ancient times, has cherished the value of peaceful development, and noticed the importance of solidarity and friendship with other countries, which can be seen in many ancient Chinese literature masterpieces. The publication of Chinese traditional literature pave the way for letting the world know more about China, which benefit for the cooperation and coordination with other countries.

When translating the poem works, translators inevitably face many problems of selecting appropriate words, focusing on the rhyme and building the artistic conception. The industrious translation scholar, Xu yuanchong, put forwardthree beauties theory - the beauty of meaning, the beauty of rhyme and the beauty of form [5]. That is to say, firstly, the translation should clarify not only the superficial meaning but the intonation of the work and make the readers fully understand the story of the poem. Then, he reckons that one of the indispensable factors of poem's high artistic achievements is rhyme, if translation loses the rhyme, the work actually abandons its soul. There is no denying the fact that the translators' interference in the process of translation work matters great.

In the recent years, as China has entered a new normal in economic development, we are in desperate need of showing our magnificent cultural achievements to the whole world. Therefore, in the speech of some occasions, the speakers are willing to cite some traditional Chinese poem to supplement and further illustrate the content. At that time, the interpreters present will confront with big challenges, if getting familiar with the smoke flare in advance, they can make through; if the speaker digresses from the fixed content and cite the poem temporarily, the interpreters have to handle this problem by his own. When interpreting poem, the interpreters not only act as a bridge connecting two languages, but also function as a narrator telling the story with in the poem and the meaning behind the words. How to explain the poem and whether mention the related background knowledge all depend on the judgments of the interpreters by evaluating the conference conditions. As long as he can express clearly, any method of explanation will be considered acceptable and reasonable. In such occasion, there is no meaning to talk about the neutral position of interpreters and no evidence to certify whether the words the interpreter use show any partiality. In the beginning, the interpreter puts understandable expressions as priority, which determines his position. Only when the interpreter thinks the content from the perspective of a Chinese listener and tries to weigh and consider the intonation of the poem and the intention of the speaker, he can actually reaches to the good poem interpretation. There are many regulation and rules of interpretation, we should apply them more flexibly. When the neutral position rule interferes with the ultimate goal of interpretation-understandable expression, it should not be taken as a measure of the quality of interpretation.

When facing poem interpretation tasks, the outstanding interpreter Zhang $\mathrm{Lu}$ can always handle them ingeniously. She once interpreted “亦余心之所向兮, 虽 九死其尤未悔” as-For the ideal that I hold near to my heart, I'd not regret a 
thousand times to die. In the Premier answers questions from reporters department. This sentence derives from Li Sao, one of the famous works of Qu Yuan, which express his strong determination and great passion for a bright future of the country and sacrifice spirits. When selecting the expression to interpret “九 死”, Zhang $\mathrm{Lu}$ didn't stick to the equivalence of the number, instead she chose-a thousand times which is more suitable for the English language usage and understandable. She once interpreted “兄弟虽有小念，不废懿亲” into differences between brothers cannot sever their bloodies. “忿” in Chinese means negative emotion and anger, but “小忿” in the poem doesn't reach the degree of anger. It was delicate for Zhang Lu responded quickly and selected-difference to substitute “小忿” and accurately show the emotion.

\subsection{Liaison Interpretation}

Contact interpretation is also called contact escort interpretation. At present, with the increasingly frequent exchanges between China and the world, a large number of political visits, industrial tourism and commercial activities, are carried out in large and medium-sized cities in China every day, and enterprises and government agencies have a large number of Foreign Affairs reception affairs. The task of liaison escort interpretation is to act as interpreter in reception, tourism and other affairs. Compared with other forms of interpretation, liaison interpreters not only responsible for the language transformation, but also for various tasks and act more like a guider.

A qualified interpreter should not only have a solid bilingual background, but also have a strong sense of responsibility, encyclopedic knowledge, cross-cultural communication awareness and natural and generous demeanor [6]. These highstandard qualities are particularly prominent in contact interpretation.

First of all, translators should have a strong sense of responsibility. After receiving the task of liaison interpretation, the interpreter shall accurately grasp the time and place of work, know it well, and make a lot of careful preparations before the interpretation work, including understanding the identity, hobbies, characteristics and other background information of the reception guests and the content of guest activities. Since liaison interpretation is often conducted in different places, interpreters often need to travel and work hard, which is also a test of physical strength. Therefore, higher requirements are put forward for interpreters' sense of responsibility and professional quality.

Secondly, interpreters should have encyclopedic knowledge. Unlike formal conference interpreting, liaison interpreting is more direct and takes longer time to get along with the host and the interpreter. Therefore, the content involved in liaison interpretation is often more casual and flexible than that in conference interpretation. For example, when the two sides have dinner together, the conversation is almost random, ranging from astronomy to geography, so the interpreter is unlikely to make advance preparation for the content of the speech. In this case, the interpreter's knowledge is very important. Imagine that if the host and the guest suddenly talked about a popular band in the 1970s or a traditional 
custom in a certain place, and the interpreter knew nothing about it, it would make the scene more embarrassing.

Thirdly, interpreters should be aware of intercultural communication. Foreign affairs activities integrate people of different cultural backgrounds, and people's perception and interpretation of the external world are influenced and restricted by culture. Cultural factors, including religion, family, tradition and values, determine how people act and adapt to the environment. It is dangerous to neglect the uniqueness of individuals and the complexity of human behavior in liaison interpretation. Not paying attention to the cultivation of cross-cultural communication consciousness often leads to errors in interpretation work, even serious consequences. For example, different nations and cultures have different habitual expressions. If a sentence arouses good feelings and friendship in one culture and is directly translated into another culture, it may cause misunderstanding and unhappiness instead.

When receiving foreign guests who have just arrived from afar, the Chinese host will ask with concern: “长途飞行而来, 路上一定很累吧”. If the interpreter translate the sentence directly into You must have been very tired after the long flight. Not only can't serve as a greeting, but also can make foreign guests (especially the older ones) feel depressed and think that they must look in a bad state. Therefore it is better to translate as I hope you have had a smooth flight.

In terms of instructions and prohibitions, Chinese is often straightforward and serious, but lacks a sense of convolution. In English, we should pay more attention to politeness and avoid the feeling of hardness. In the process of contact interpretation, interpreters should try to avoid above conditions, for example, when interpreting “请注意”,-Ladies and gentlemen, may I have your attention please? is much better than-attention, please!. And similarly when interpreting “此门不通”,-“please use the other door” is much more euphemistic than “no entry through this door".

When being praised or thanked by others, Chinese culture chooses to show modesty and politeness, such as “这没什么, 都是我应该做的”, “哪里那里, 是 不足挂齿的小事”, “我做的还不够好” etc. If interpreting directly into “it's nothing", "this is what I should do", "there is still a lot to improve" and so on will make foreign guests feel insincere and over affectation, so it should be translated into "thank you for your kind words", "it is my pleasure", "I feel flattered" and so on according to English cultural habits.

Kramsch pointed out in his works that "Language is the principle means whereby we conduct our social lives. When it is used in contexts of communication, it is bound up with culture in multiple and complex ways." (Kramsch, 2000: 3), it shows that a qualified interpreter should pay attention to the promotion of cultural awareness and cross-cultural communication ability while forging his own language ability.

Finally, the interpreters should have a natural and generous manner. Mastering the basic norms of behavior in foreign affairs activities, such as punctuality, dress code, neat appearance, friendly attitude, proper speech, and attention to 
etiquette, are all important parts of liaison interpretation. A good interpreter should show a good outlook in the foreign affairs reception activities, play an outstanding role of "Diplomat", and make the foreign guests feel happy in body and mind.

\subsection{International Business Negotiation Interpretation}

International business negotiation is a common but complex human activity. $\mathrm{Ne}-$ gotiators from different countries participate in this business activity and exchange views with each other in order to reach their own interests. "Through continuous and conscious efforts, the agreement is finally concluded and implemented". The both sides of the negotiation have one goal in common, that is to gain the best interests. Therefore, it is regular to see the negotiators arguing even fighting with each other. Negotiations are compared to "war on the table". Under this circumstance, interpreters should never obey the neutral position rule but to deal with the problems flexibly. If the parties start to say some disrespectful words, the interpreter should aware that the situation may go to a disharmonious trend and should hold back the tendency. The interpreter will never directly translate the original words but change a mild and roundabout method to communicate with the other party, by which the interpreter will not only prevent a potential struggle but also may help facilitate the cooperation. In such situation, there is no meaning to censure the interpreter for his position problem.

From the perspective of the parties who initiate and implement intercultural communication activities, their opinions on the position of interpreters are also full of contradictions and problems. It is true that interpretation is in the final analysis the act of providing language services for the parties. As a client enjoying the services, he has the right to ask the interpreter to remain objective and neutral, because favoring one party means unfairness to the other. However, although there is no doubt about the legitimacy of this requirement in theory, its reliability in reality is questionable. In real interpreting events, we often find the parties involved

The requirements for the interpreter's position are often ambiguous, inconsistent or even contradictory. They hope that the interpreter will be complete, accurate, impartial and objective in his/her translation for the other party, but they expect that the interpreter's perspective and method will be beneficial to them when serving their own party, which can be neutral. If an interpreter is hired at his own expense, it is easier to think that he is the "legitimate" user of interpretation services. The interpreter should think more about himself, and often ask the interpreter to sit on his side (sometimes the arrangement of the interpreter's seat can also reflect a certain position), become his "alliance", and act as an assistant or adviser for himself when necessary. At that time, not only act as the transformation of language, the interpreters have to function as a staff and consider the demands of service users. Otherwise, they may face the criticism of impartiality in the process of interpretation and can't receive the pay they de- 
serve.

In one case, Mr Chen took part in the business negotiation between China and foreign countries. During this period, the foreign side put forward an obviously unreasonable and excessively high request. The Chinese representative said angrily: “XXX, 这老外发昏了, 想吃天鹅肉”. The foreign side looked at Mr Chen, who translated: “this is really too much. If you insist, I'm afraid we can't go." $\mathrm{He}$ used the more acceptable way to express the dissatisfactions and demands of the Chinese side and wittily solve the potential problem.

\section{Conclusions}

No matter from the macro context of cross-cultural communication, or from the specific communication events, no matter from the relationship between the translator and the parties, or from the behaviour of the translator itself, whether from the perspective of the choice of the translator's self-position, or from the analysis of the actual expectations of the translator's position, it is difficult for the translator to maintain consistency in cross-cultural communication events The position of complete neutrality may be approached to one of the parties at some time, either obviously or slightly, or explicitly or implicitly. Of course, this tendency does not mean that the other party is regarded as the opposite, and it may also be pendulum like and contextualized. The absolute neutrality of the translator is just the ideal construction of wishful thinking. As the natural people in the society, the growth of translators must be branded with strong culture colour, including the mode of thinking, the language habits, and the postures. Translation, substantially, is a cross-culture communication activity, and as long as it should be carried out by human, it will inevitably effected by the human factors. Interpretation activity cannot happen in a vacuum environment, apart from the factors of the interpreters themselves, it also influenced by the outer surroundings including the type of the interpretation, the background information of conference, participants, the time and location of interpretation. It is understandable for the international society and the translation association to set the neutral position for the translators, which is also beneficial for the novitiates to shape the right attitudes to core meanings of translation, however, the absolute neutral position is impossible to achieve in practice. Moreover, the standard of neutral translation is obscure and hard to illustrate clearly what kind of action of interpreters should be regarded as impartial and who should be responsible for the supervision task. Due to the complexity of the interpretation activity, the regulation hardly covers all the possible situations in reality, and therefore, neutral position gradually becomes a rule in the paper.

Neutral position hinders the performance of interpreters. In the industrial revolution period, the invention of machine greatly increased the productivity level and also altered people's way of thinking. Many entrepreneurs started treat the workers as machine and force them to do excessive quantity of work with low pay. Gradually, the thought-people equal to machine spread and permeated 
into every field in the society. So did in translation industry. People at that time considered translators only as the tools in the communication process of different languages and required them to obey the original content as much as possible. With the development of economy and culture, people started to rethink and redefine the human group and recognized the power of human's subjectivity and creativity excel machine. In the translation field, people began to find the importance of translators and gave them more space to polish the translation work so as to show better results rather than confining them to the prison of the original language and target language.

The subjectivity of the interpreter in the process of interpretation is an objective existence, which runs through the process of interpretation all the time [7]. Translation is the place where two cultures encounter, and the process of translation is the process of negotiation between the two cultures. As the intermediary of two cultures, the translator's identity and cultural orientation are inevitably reflected in his translation. Translation, as an objective practice, has a certain purpose, so the interpreter will choose the way of interpretation according to the needs of the purpose [8]. It can be seen from the subjectivity of the interpreter that interpretation is not only influenced by the cultural value orientation of the interpreter, but also by the temperament type of the interpreter, which will affect his understanding of the discourse, the way of handling and the choice of strategies. Therefore, the author believes that it is impossible to achieve the neutrality of the interpreter in the process of interpretation without the influence of personal preference, national consciousness and other factors and also the neutrality restrain translators to produce extraordinary works.

\section{Fund}

This paper is the outcome of China Three Gorges University Graduate School Project. Project Name: Interpreting Ability Training of MTI Students. Project item: SDYJ201919.

\section{Conflicts of Interest}

The author declares no conflicts of interest regarding the publication of this paper.

\section{References}

[1] Andrew, C. and Vermeer, H.J. (1996) A Skopos Theory of Translation: (Some Arguments For and Against). TEXTconTEXT-Verlag, Heidelberg, 136.

[2] Pink, D.H. (2009) Drive: The Surprising Truth about What Motivates Us.

[3] Honig, H.G. (2010) Positions, Power and Practice: Functionalist Approaches and Translation Quality Assessment. Current Issues in Language and Society, 4, 6-34. https://doi.org/10.1080/13520529709615477

[4] Hermans, T. (2014) Positioning Translators: Voices, Views and Values in Translation. Language and Literature, 23, 285. https://doi.org/10.1177/0963947014536508

[5] Jiang, H. (2013) The Ethical Positioning of the Interpreter. Fédération des Traduc- 
teurs (fit) Revue Babel, 59, 209-223. https://doi.org/10.1075/babel.59.2.05jia

[6] Li, Y.B. (2018) Translators' Subjectivity in Commercial Advertising Translation. Advances in Economics, 53.

[7] Risku, H., Pichler, T. and Wieser, V. (2017) Transcreation as a Translation Service: Process Requirements and Client. Across Languages and Cultures, 18, 53-77. https://doi.org/10.1556/084.2017.18.1.3

[8] Sun, Y.F. (2014) Cross-Cultural Translation: Attitudes, Feelings and Affective Interactions. Neohelicon, 41, 275-292. https://doi.org/10.1007/s11059-013-0225-6 